\title{
Hervé Guillemin, Stéphane Tison, Nadine Vivier (éd.), La foi dans le siècle. Mélanges offerts à Brigitte Waché
}

Presses universitaires de Rennes, coll. « Histoire », 2009, 398 p.

\section{Claude Langlois}

\section{(2) OpenEdition \\ Journals}

Édition électronique

URL : http://journals.openedition.org/assr/23496

DOI : $10.4000 /$ assr.23496

ISSN : $1777-5825$

Éditeur

Éditions de l'EHESS

Édition imprimée

Date de publication : 31 décembre 2011

Pagination : 173

ISBN : 9782713223273

ISSN : 0335-5985

\section{Référence électronique}

Claude Langlois, « Hervé Guillemin, Stéphane Tison, Nadine Vivier (éd.), La foi dans le siècle. Mélanges offerts à Brigitte Waché ", Archives de sciences sociales des religions [En ligne], 156 | octobre-décembre 2011, document 156-50, mis en ligne le 15 février 2012, consulté le 21 septembre 2020. URL : http:// journals.openedition.org/assr/23496; DOI : https://doi.org/10.4000/assr.23496 


\title{
Hervé Guillemin, Stéphane Tison, Nadine Vivier (éd.), La foi dans le siècle. Mélanges offerts à Brigitte Waché
}

Presses universitaires de Rennes, coll. « Histoire », 2009, 398 p.

\author{
Claude Langlois
}

\section{RÉFÉRENCE}

Hervé Guillemin, Stéphane Tison, Nadine Vivier (éd.), La foi dans le siècle. Mélanges offerts à Brigitte Waché, Presses universitaires de Rennes, coll. « Histoire», 2009, 398 p.

1 Tout livre d'hommage offre avantage et inconvénient. Avantage, il permet de mieux cerner une trajectoire scientifique, avec ses parrainages, attendus ou insolites. Les hommages, à ce titre, peuvent nourrir la connaissance de la sociabilité universitaire et de ses réseaux intriqués. L'inconvénient évident provient de l'hétérogénéité des articles, malgré la volonté de ceux qui les réunissent de leur donner une cohérence. Ajoutons encore la durée de vie accrue de chacun, universitaires compris, qui fait du départ à la retraite et de l'abandon de lourdes charges administratives, plus d'une fois, le point de départ fructueux pour des travaux d'écriture, impossibles auparavant. Ce qui rend tout bilan historiographique, sinon incertain, au moins incomplet.

2 L'ouvrage, d'excellente facture, consacré à Brigitte Waché, historienne connue par sa thèse sur Mgr Duchesne, illustre parfaitement cette difficulté. Pour le premier versant l'historiographie intellectuelle -, on retiendra la chaleureuse présentation des travaux de B. Waché par Charles Molette, écho à vingt ans de distance, de la publication d'hommages à Charles Molette, due à Brigitte Waché (L'histoire des croyants. Mémoire vivante des hommes. Mélanges Charles Molette. Articles rassemblés par Brigitte Waché, 2 vol., XXII-950). Pour le second, chacun lira à sa manière ces vingt-sept articles selon ce 
qu'il connaît des participants - il ne sera pas surpris qu'Annette Becker parle des cultures de guerre, d'Apollinaire en l'occurrence, ni que Marie-Thérèse Cloître bretonnise (Maro evit ar vro, "Morts pour la France », l'étude porte sur les monuments aux morts.) - ou ce qui peut raviver ses curiosités propres. J'ai pris ainsi un plaisir particulier à la présentation de la Jeanne d'Arc du peintre La Fresnaye (1911) parce que, récemment, je venais de revisiter la Jeanne d'Arc de Delteil (1925). On peut aussi considérer ces mélanges comme l'occasion d'une remise à niveau de connaissances sur un secteur spécifique - ici l'histoire religieuse entre les $\mathrm{XVI}^{\mathrm{e}}$ et $\mathrm{Xx}^{\mathrm{e}}$ siècles - à partir d'une sélection aléatoire qui offre l'occasion de mélanger les générations et de se trouver au contact de recherches en cours, par exemple Cédric Paulin, essayant, de composer la figure morcelée d'un « passeur intellectuel » manceau, l'abbé André Sevin (1896-1967). La difficulté de mettre en avant un article plutôt qu'un autre tient aussi au genre littéraire qui conduit des auteurs contingentés à donner la priorité à des approches monographiques. Deux articles au moins me paraissent devoir retenir l'attention, ils ont en commun de retravailler deux ouvrages récemment parus. Le premier, de Didier Boisson, a trait aux conversions de prêtres et religieux catholiques au calvinisme durant le xvIII ${ }^{e}$ siècle (sur le même registre, Hugues Dhaussy, Les enjeux politiques d'une conversion. Les relations épistolaires entre Jean Calvin, Jean Macar et François d'Andelot en 1558). La source est sûre, puisqu'il s'agit de la chambre des prosélytes de Genève, institution qui fonctionne comme un sas créé pour apprécier les motivations des convertis. L'intérêt de l'étude provient tout autant de l'échantillon de clercs catholiques mal dans leur religion que de la rhétorique de leurs motivations et plus encore de l'examen de leur niveau intellectuel, permettant la sélection des meilleurs. Le second article est dû à Hervé Guillemin, le récent historien de la méthode Coué. Notre revue aurait reçu cette étude sur les aspects religieux de ladite méthode - qui a fait fureur au lendemain de la guerre de 1914 - qu'elle n'aurait eu qu'à se féliciter de sa clarté d'exposition et de sa rigueur d'investigation, plus encore de sa manière fort suggestive de situer les aspects religieux d'une méthode d'apparence toute laïque, dans la recomposition du champ des thérapies spirituelles qui s'opère alors, aussi bien en Europe qu'aux États-Unis. 